\title{
Incidence of early burn-induced effects on liver functionas reflected by the plasma disappearance rate of indocyanine green: a prospective descriptive cohort study
}

\author{
Ingrid Steinvall, Mats Fredrikson, Zoltan Bak and Folke Sjöberg
}

\section{Linköping University Post Print}

\begin{abstract}
N.B.: When citing this work, cite the original article.
\end{abstract}
Original Publication:

Ingrid Steinvall, Mats Fredrikson, Zoltan Bak and Folke Sjöberg, Incidence of early burninduced effects on liver functionas reflected by the plasma disappearance rate of indocyanine green: a prospective descriptive cohort study, 2012, Burns, (38), 2, 214-224.

http://dx.doi.org/10.1016/j.burns.2011.08.017

Copyright: Elsevier

http://www.elsevier.com/

Postprint available at: Linköping University Electronic Press

http://urn.kb.se/resolve?urn=urn:nbn:se:liu:diva-70059 


\section{Incidence of early burn-induced effects on liver function as reflected by the}

plasma disappearance rate of indocyanine green: A prospective descriptive cohort study

Ingrid Steinvall RN, PhD, ${ }^{1,2}$ Mats Fredrikson PhD,${ }^{2}$ Zoltan Bak MD, PhD,${ }^{1,3}$ Folke Sjoberg, $\mathrm{MD}, \mathrm{PhD}^{1,2,3}$

${ }^{1}$ The Burn Unit, Department of Hand and Plastic Surgery,

${ }^{2}$ Department of Clinical and Experimental Medicine, Faculty of Health Sciences, Linköping University,

${ }^{3}$ Department of Anesthesiology and Intensive Care,

All at Linköping University Hospital, Linköping, 58185, Sweden

Corresponding author: Ingrid Steinvall (ingrid.steinvall@lio.se)

Address: Burn Unit, Linköping University Hospital, Linköping, 58185, Sweden

Phone: +46 (0) 101031281

Keywords: Burns, organ dysfunction, hepatic dysfunction, plasma disappearance rate of indocyanine green, age, cardiac index, sepsis. 


\section{Abstract}

Organ dysfunction and failure are important for burned patients as they increase morbidity and mortality. Recent evidence has suggested that organ injuries are occurring earlier after burns, and are more common than previously thought. In this study we have assessed the extent to which liver function, assessed by the plasma disappearance rate of indocyanine green $\left(\mathrm{PDR}_{\mathrm{ICG}}\right)$, is affected in patients with severe burns. This is a prospective, descriptive exploratory study at a national burn centre. Consecutive adult patients with a percent total body surface area burned (TBSA\%) of $20 \%$ or more, were examined prospectively by dynamic $\left(\mathrm{PDR}_{\mathrm{ICG}}\right)$ and static liver function tests (plasma: bilirubin concentration, prothrombin complex, and alanine aminotransferase and alkaline phosphatase activities). Early liver dysfunction was common, as assessed by both dynamic (7 of 17) and static liver function tests (6-17 of 17). A regression model showed that changes in $\mathrm{PDR}_{\mathrm{ICG}}$ were associated with age, TBSA\%, plasma bilirubin concentration, plasma C-reactive protein concentration, and cardiac index. Persistent and advanced hepatic dysfunction was associated with mortality. The $\mathrm{PDR}_{\mathrm{ICG}}$ seems to give a comprehensive assessment of liver function after major burns. Hepatic dysfunction seems to be as common as dysfunction in other organs. We interpret the recorded effects on liver function as part of a multiple organ dysfunction syndrome, primarily induced by the burn itself. However, this needs to be further investigated. 


\section{Introduction}

The liver plays a central role after burns, both in the host's defence response and as a target for remote organ dysfunction in systemic inflammation. It is not surprising, therefore, that patients with pre-existing liver disease have an almost doubled risk of mortality compared with burned patients with similar histories, injuries, and medical profiles [1].

Thermal injury can cause liver damage by several mechanisms (hypoperfusion, proinflammatory cytokines, or other signals of cell death, formation of oedema, and fatty changes). Yet, the incidence of liver dysfunction after burns seems to be low, and it does not qualify on the list of top 10 clinically most relevant complications from the American Burn Association database [2]. A few studies have reported the results of serum analyses that have assessed static liver dysfunction among adult burned patients. In a group with $30 \%$ TBSA and $15 \%$ mortality, hepatic dysfunction was detected in 3.5\% [3]. Another study showed a 36\% incidence of liver failure, the reported onset of which was in the second week (median day 9) after a lethal burn injury [4]. In a recent paper, enlargement of the liver and impaired protein synthesis have been shown to develop early among children with major burns, and the extent of that dysfunction correlated with the size of the burn. The activities of hepatic enzymes (serum aspartate aminotransferase (AST), and alanine aminotransferase (ALT)) were increased two-fourfold immediately after the burn, and took four to six weeks to return to the reference range, which suggested burn-induced liver damage [5].

\subsection{Assessment of liver function}

Traditionally assessment of liver function is based on static laboratory tests that provide indirect measures of hepatic function, while dynamic tests such as the plasma disappearance rate of indocyanine green $\left(\mathrm{PDR}_{\mathrm{ICG}}\right)$, provide measures of the actual functional state of the liver at the time of the measurement [6]. PDR ${ }_{I C G}$ has been shown to be a good predictor of 
survival in critically ill patients [7-10], and the method has been validated in several studies. Invasive PDR ${ }_{\text {ICG }}$ reflects clearance of ICG from the blood of critically ill patients [11]. Noninvasive $\mathrm{PDR}_{\mathrm{ICG}}$ has been compared with invasive $\mathrm{PDR}_{\mathrm{ICG}}$ in critically ill patients during fluid loading and infusion of dobutamine [12], and in recipients of liver transplants [13], but has not previously been used in studies on patients with burns.

The aim of the present study was to assess the early (< two weeks after injury) burninduced effects on dynamic (PDR $\mathrm{ICG}_{\text {) }}$ ) and static (plasma bilirubin concentration, activities of AST, ALT, and alkaline phosphatase (AP), and prothrombin complex) markers of liver function, and relate these changes to important burn indices and dysfunction in other organs. We set up the following hypotheses: First, liver dysfunction develops soon after a severe burn. Secondly, the non-invasive $\mathrm{PDR}_{\mathrm{ICG}}$ method can capture changes in liver function that may be caused by the specific aspects of a burn injury, such as TBSA\% and perhaps inhalation injury. It also adds new information as compared to conventional liver function tests regarding burn induced liver effects.

\section{Patients and methods}

\subsection{Design, and selection of patients}

During a four-year period (2006-2009) consecutive adult patients (18 years and over)

admitted to a national burn centre (the Linköping University Hospital Burn Unit) with thermal burns involving $20 \%$ or more of the total body surface area (TBSA\%) were included in this prospective explorative cohort study.

Criteria for exclusion were: allergy to ICG or iodine; pregnancy; superficial burns that did not require arterial and central intravenous lines or central haemodynamic monitoring; and patients who died within the first 2 days. 


\subsection{Measurements}

$\mathrm{PDR}_{\mathrm{ICG}}$ as an indicator of liver function was measured using the non-invasive liver function monitoring system (LiMON, Pulsion Medical Systems, Munich, Germany), on days 1, 2, 3, 5, 7, 9, and 14 after injury. A dose of ICG $0.5 \mathrm{mg} / \mathrm{kg}$ body weight was given through a central venous line, and measured by a transcutaneous sensor (Sensor PV50100) on a finger or toe. Reference values used for $\mathrm{PDR}_{\mathrm{ICG}}$ were $18 \%-25 \% /$ minute [13]. We chose to group the patients according to how many of their measurements of $\mathrm{PDR}_{\mathrm{ICG}}$ were below the lower reference value (18\%/minute). "No liver dysfunction" indicated patients with none or only one $\mathrm{PDR}_{\mathrm{ICG}}$ value below the reference, whereas "liver dysfunction" indicated patients with

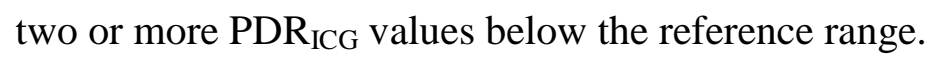

Measurements of central haemodynamics and extravascular lung water by transpulmonary thermodilution (PiCCO, Pulsion Medical Systems Munich) were made at the same time as liver function was measured. Standard laboratory tests were drawn from an arterial line on the same days, and analysed in the University Hospital laboratory. The lowest $\mathrm{PaO}_{2}$ indicated which $\mathrm{PaO}_{2} / \mathrm{FiO}_{2}$ value to list as the worst daily value, and the lowest arterial $\mathrm{pH}$ value indicated which base excess value to use. The highest value each day was chosen for expiratory minute volume, and it is presented as $\mathrm{ml} / \mathrm{kg}$ predicted body weight [14].

Details of vital signs, nutrition, and organ dysfunction, including sepsis, were recorded separately. Information about previous medical conditions was extracted from medical charts, and clinical data such as TBSA\% and age were recorded in the prospectively maintained local burn registry [15]. The diagnosis of inhalation injury was verified by bronchoscopy. Sepsis was classified according to the international intensive care definition [16]. The Sequential Organ Failure Assessment score (SOFA) was used to assess organ dysfunction [17]. The neurological part of SOFA was left out because of the difficulties in assessing the Glasgow coma scale in sedated patients. For this study multiple organ failure was defined as 3-4 score points in 2 or more organ dimensions of the SOFA score [18]. Organ dysfunction was defined 
as a SOFA dimension score point of over zero. The definition used for enteral dysfunction was "inability to continue enteral feeding for more than 24 hours because of enteral feeding intolerance (persistent residual)". It was derived from one of the criteria for sepsis from the American Burn Association consensus conference to define sepsis and infection [19]. Acute respiratory distress syndrome (ARDS) was graded according to the lung injury score by which scores that exceed 2.5 indicate a severe lung injury [20].

The regional ethics committee (the Regional Ethical Review Board in Linköping) waived the need for their approval for descriptive and explorative studies that not include procedures that not are considered as ordinary burn care.

\subsection{Burn care}

Patients were treated in a protocol based way according to our usual regimen [15], including early excision and grafting, standard ventilation, fluid management, early enteral nutrition, and laboratory assessment according to a preset protocol. Different aspects of this have previously been described [21-24]. Ringer's acetate was used for fluid resuscitation in volumes according to the Parkland formula (4 ml/kg body weight (BW) x TBSA\%), with adjustments for individual variations in hemodynamic variables, aiming at least for a mean arterial pressure of $70 \mathrm{mmHg}$ and urine output of more than $1 \mathrm{ml} / \mathrm{kg} \mathrm{BW} /$ hour. Plasma and 6\% hydroxyethyl starch (Voluven®, Kabi Fresenius, Frankfurt, Germany) were used additionally in cases of circulatory instability despite the need of very large fluid volumes. Blood was given when blood haemoglobin levels were below $90 \mathrm{~g} / \mathrm{L}$. For adrenergic support norepinephrine, dopamine, and dobutamine were used as needed. The patients were not treated with any specific anabolic agent. Insulin was provided intravenously in case of high plasma-glucose (above $10 \mathrm{mmol} / \mathrm{L}$ ). Propranolol 80-160 mg/day was given as an anticatabolic agent to the patients with the most severe burns, starting at the end of the first week after injury. Nutrition was provided enterally from day 1 , starting with continuous enteral feeding $20 \mathrm{ml} /$ hour, and increased to full enteral nutrition on day two or three using standard 
enteral formula together with enteral fat emulsion and intravenous glucose $100-200 \mathrm{~g} / \mathrm{day}$. The caloric goals were assessed by indirect calorimetry.

\subsection{Statistics}

Data were analysed with the help of STATA (STATA v10.1, Stata Corp. LP, TX, USA), and are presented as median (10- 90 centiles), unless otherwise stated. The significances of differences between groups were assessed using the Mann Whitney U-test and Fisher's exact test, as appropriate. The Wilcoxon matched pairs test was used assess the significance of differences over two days. Spearman's rank correlation was used to assess possible associations between two variables (for example, a measurement value from day one (or day 1-3) and a worst measurement value from the following days). Reference values for men were given in graphs of laboratory analyses as 15 of the 17 patients were men.

We used a multiple regression model for longitudinal data for analysing associations between PDR $_{\mathrm{ICG}}$ and physiological markers after a burn. The dependent variable was PDR $_{\mathrm{ICG}}$ (\%/minute) measurements 1-14 days after injury; the group (panel) variable was patient identity; and the time variable was day after injury. Independent variables were included stepwise, and only variables that contributed significantly to the final result were retained in the model. Probabilities of less than 0.05 were accepted as significant.

The model was designed to cover: general health (age and pre-existing medical condition, including history of alcohol misuse); specific aspects of a burn injury (TBSA\%, inhalation injury); static tests of liver function (plasma bilirubin concentration (excretion), plasma prothrombin complex (synthesis), and plasma ALT (hepatocellular integrity), and AP (cholestasis) activity); physiological status (cardiac index (circulation/perfusion), plasma Creactive protein concentration (inflammation), arterial blood partial pressure of oxygen (oxygenation)); and organ dysfunction (SOFA dimensions: cardiovascular, respiratory, coagulation, renal, and hepatic). Model overall $\mathrm{R}^{2}, \mathrm{R}^{2}$ between subjects, coefficients and probabilities from the regression model for longitudinal data are shown. The relative 
percentage (beta part) of the contribution from the included variables to a hypothetical $\mathrm{R}^{2}$ 1.00 was calculated $\left(\left(1\right.\right.$-overall $\left.\mathrm{R}^{2}\right)+$ overall $\left.\mathrm{R}^{2}\right)$ using the standardised coefficients (beta) from linear regression. 


\section{Results}

Seventeen adult patients with thermal burns involving 20\% TBSA or more were included in the study (Table 1). Nineteen patients were excluded, because of early death $(n=4)$ and superficial burns not requiring arterial lines, central lines, and central haemodynamic monitoring (Fig. 1). No patient was excluded because of allergy or pregnancy.

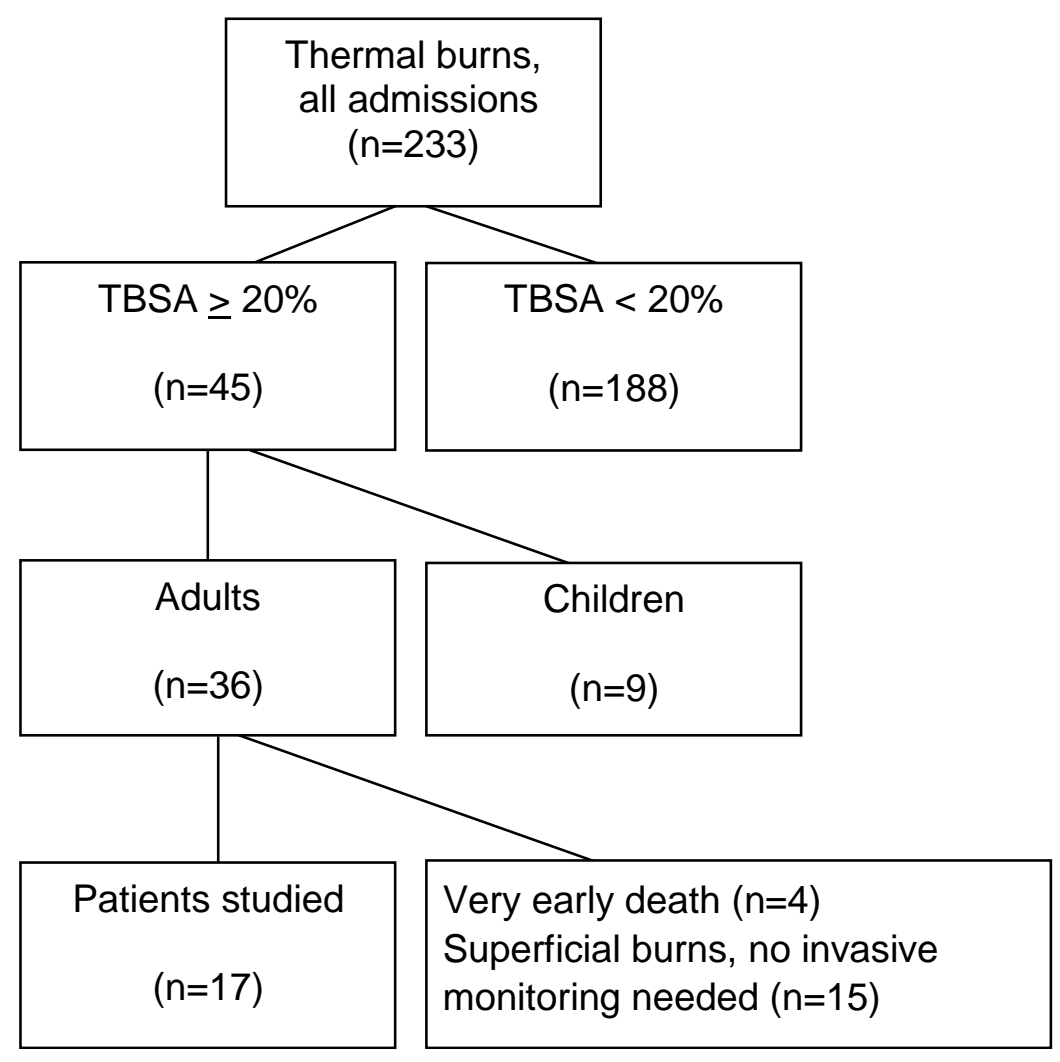

Figure 1. Algorithm showing selection of patients.

\subsection{Details of patients}

Eight of the patients were considered to be in good physical health at the time of injury.

Documented pre-existing medical conditions were: hepatitis $C(n=2)$; myocardial infarction $(n=2)$; cerebrovascular accident $(n=1)$; hypertension $(n=2)$; epilepsy $(n=2)$; diabetes $(n=3)$; renal failure $(n=1)$; alcohol misuse $(n=4)$; and chronic obstructive pulmonary disease $(n=2)$, and they were evenly distributed throughout both groups (no liver dysfunction/liver 
dysfunction). The patients who died were older than those who survived (77 (70-79) years compared with 41 (20-76) years, $p=0.02)$. Sixteen of the patients were operated on, and the first operation took place a median of 2 days (2-4) after injury. All the patients required antibiotics during the study period and they were started a median of 4 (1-8) days after injury. There was no obvious association between antibiotics given and effects on static and dynamic liver function tests. Twelve of the 17 patients were treated with propranolol, with start on (median) day 7 (3-11). Seven of these patients were given $80 \mathrm{mg}$ per day, and five were given $160 \mathrm{mg}$ per day. The two patients who had the lowest PDR $_{\mathrm{ICG}}$ values and died early were not treated with propranolol. A third patient who had low and decreasing PDR $\mathrm{ICG}_{\mathrm{IC}}$ values during the study period was given propranolol from day 11 , and showed partial recovery in PDR $_{\text {ICG, }}$ but there was no consistent pattern in $\mathrm{PDR}_{\mathrm{ICG}}$ changes among the patients after the treatment with propranolol was started.

\subsection{Dynamic liver function: $\mathbf{P D R}_{\text {ICG }}$}

Early transient liver dysfunction as assessed by PDR $_{\text {ICG }}$ was common (7/17, 41\%) (Fig. 2). The regression model showed that changes in liver function (measured as PDR $_{I C G}$ ) after serious burns are associated with age, TBSA\%, plasma bilirubin concentration, plasma Creactive protein, and cardiac index (Table 2).

Seven patients were classified as having hepatic dysfunction, with median onset (PDR ${ }_{\text {ICG }}$ below 18\%/minute) on day $1.0(1.0-3.8)$ Three of these patients showed decreasing values during the study period; two of them died of multiple organ failure, and their lowest

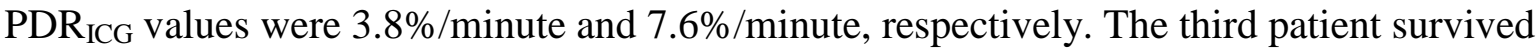
with a lowest value of 5.3\%/minute on day 9 after injury, but showed partial recovery measured after the study-period (12\%/minute $\mathrm{PDR}_{\mathrm{ICG}}$ on day 28$)$; no more measurements were done after this. The remaining four patients with liver dysfunction had higher values than the patients who died soon after injury, and their measurements varied over and under the lower reference limit during the study period. Fig. 3 shows PDR $_{I C G}$ among the patients 
who survived and the patients who died during length of stay. Fig. 4 shows PDR $_{\text {ICG }}$ among young and old patients.

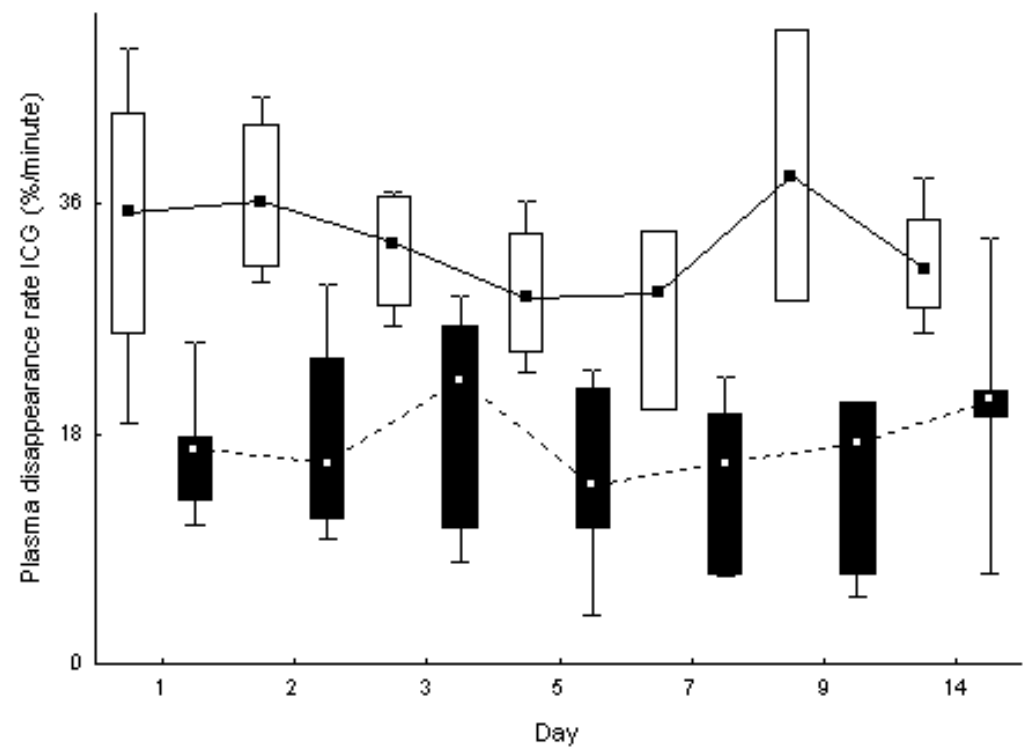

Figure 2. Plasma disappearance rate, days 1-14 after injury. Patients classified as having no liver dysfunction ( $n=10$; open boxes); Patients classified as having liver dysfunction $(n=7$; closed boxes). Squares indicate the median, boxes extend from $25^{\text {th }}$ to $75^{\text {th }}$ centile, and error bars show the $10^{\text {th }}$ and $90^{\text {th }}$ centiles.

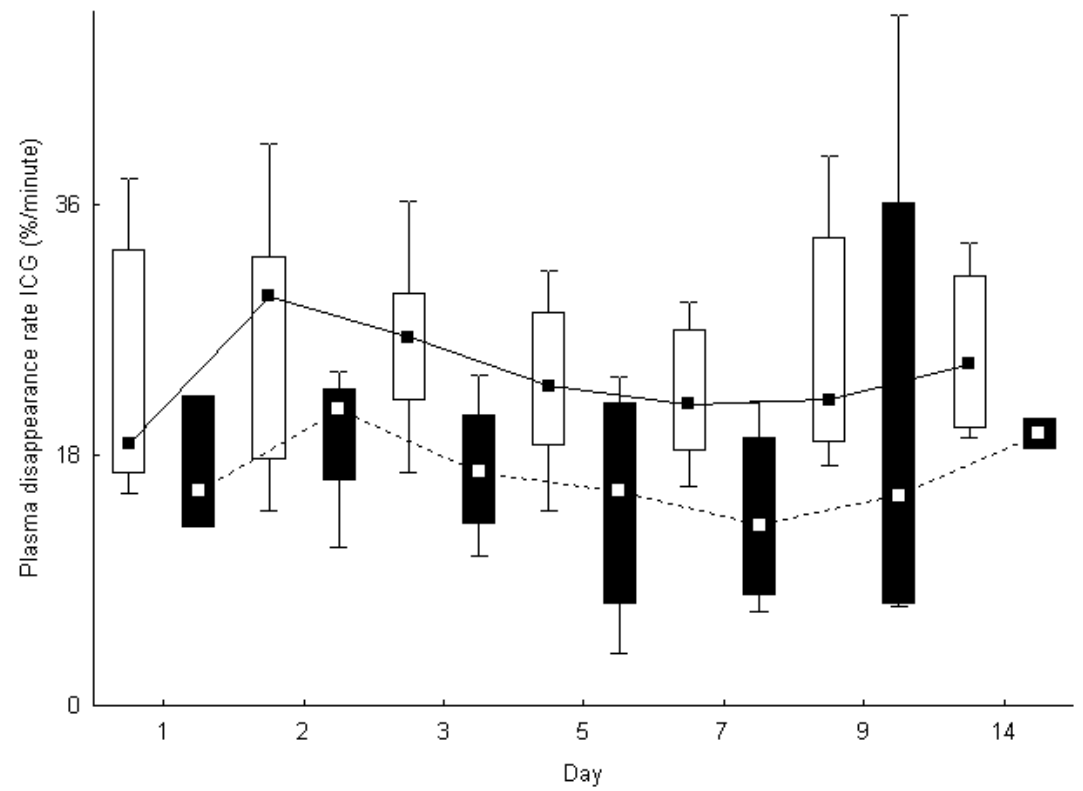

Figure 3. Plasma disappearance rate, days 1-14 after injury. Patients who survived ( $n=13$; open boxes); Patients who died during length of stay ( $n=4$; closed boxes). Squares indicate the median, boxes extend from $25^{\text {th }}$ to $75^{\text {th }}$ centile, and error bars show the $10^{\text {th }}$ and $90^{\text {th }}$ centiles. 


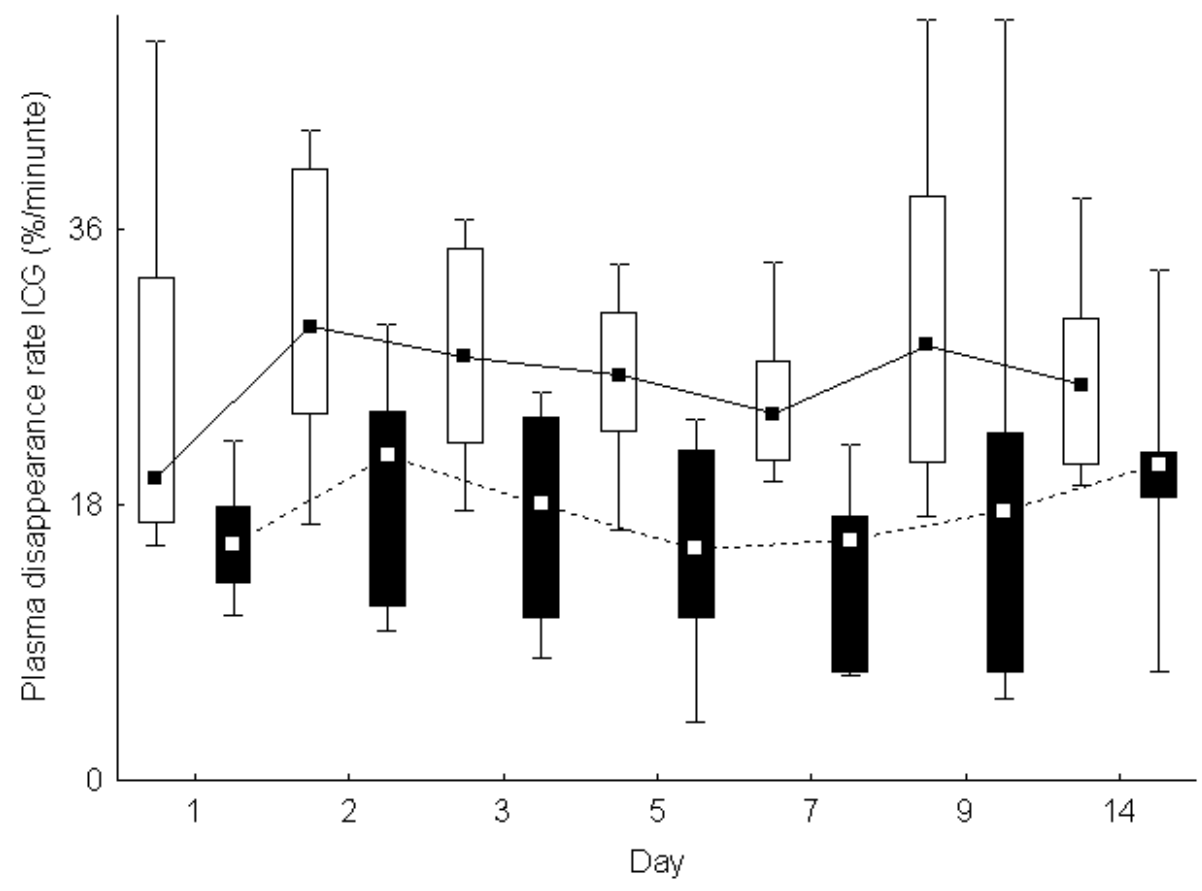

Figure 4. Plasma disappearance rate, days 1-14 after injury. Patients younger than 60 years ( $n=10$; open boxes); Patients 60 years and older ( $n=7$; closed boxes). Squares indicate the median, boxes extend from 25th to 75th centile, and error bars show the 10th and 90th centiles.

Ten patients were classified as having no liver dysfunction, four of whom had no

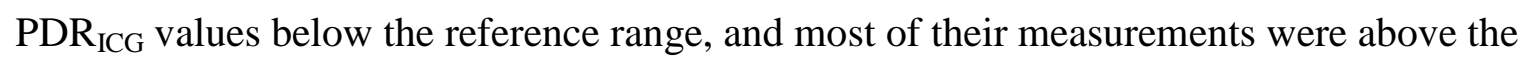
upper reference limit after day one. Six patients had a single $\mathrm{PDR}_{\mathrm{ICG}}$ value below the reference value, but most of the measurements were within the range, being above it in four cases. Two of the patients who had a single PDR ${ }_{I C G}$ value below the reference range (15.4\%/minute on day 1 , and $16.7 \% /$ minute on day 7 , respectively) died seven and nine weeks after injury of multiple organ failure. The patients who developed liver dysfunction were older than those who did not, but there were no other significant differences between them in general characteristics (Table 1), resuscitation variables, or measures of the central circulation on day 1 (data not shown). Fig. 5 shows measures of central haemodynamics and extravascular lung water during the study period and Table 3 shows measures on day 1 divided between survivors and non survivors. 

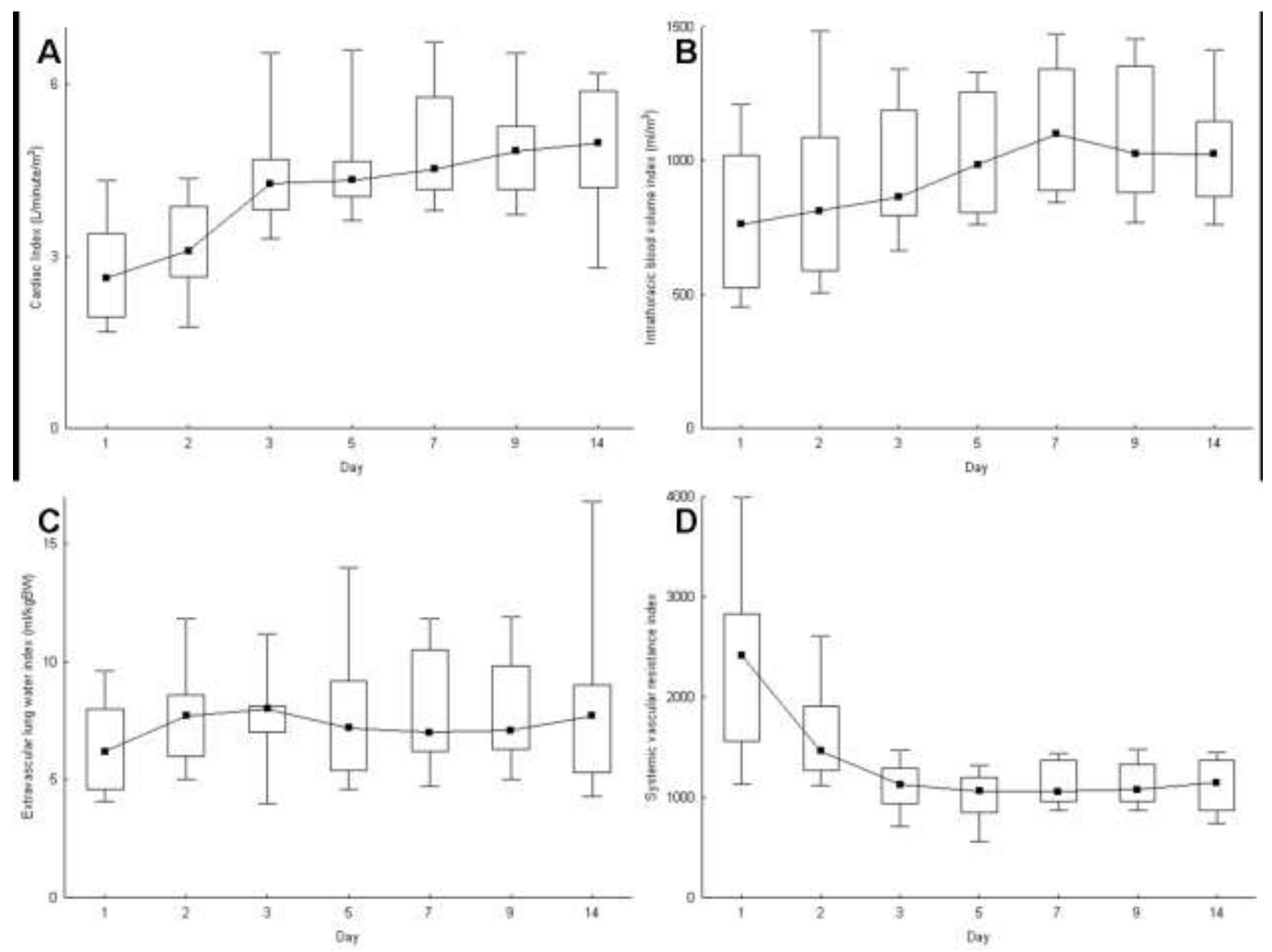

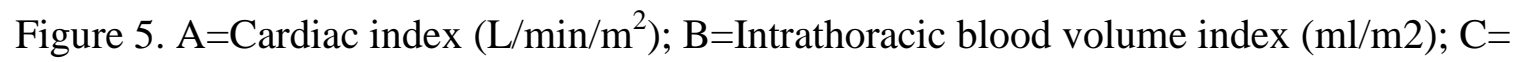
Extravascular lung water index $(\mathrm{ml} / \mathrm{kg})$; and $\mathrm{D}=$ Systemic vascular resistance index (dyn $\mathrm{s}$ $\mathrm{cm}^{-5} \mathrm{~m}^{2}$ ), measured on days $1-14$ after injury $(\mathrm{n}=17)$. Squares indicate the median, boxes extend from $25^{\text {th }}$ to $75^{\text {th }}$ centile, and error bars show the $10^{\text {th }}$ and $90^{\text {th }}$ centiles.

Mortality within the first three weeks after injury $(n=2)$ was associated with persistent liver dysfunction. Other than that, we did not find early measurements of PDR $\mathrm{ICG}_{\text {to }}$ to predictive, and we found no significant correlations between resuscitation indicators on day 1 and the lowest PDR $\mathrm{ICG}_{\mathrm{IC}}$ measurement during the whole study period (data not shown).

\subsection{Static measures of liver function}

There were no significant differences in measurements of static liver function from day1, from the median, or from the highest value from each patient during the study period, between the group of patients who developed liver dysfunction and those who did not (data not shown). 
The plasma bilirubin concentration was increased $(20 \mu \mathrm{mol} / \mathrm{L}$ or more $)$ in 8 patients, four from each group. All 17 patients had plasma prothrombin complex values above the reference international normalised ratio (INR) of 1.2. Plasma ALT activity was above the reference $(1.2 \mu \mathrm{kat} / \mathrm{L})$ in 6 patients ( 3 from each group), and in all cases the increase was preceded or paralleled by sepsis. Plasma AP activity (1.90 $\mu \mathrm{kat} / \mathrm{L})$ was increased in 11 patients (Fig. 6).
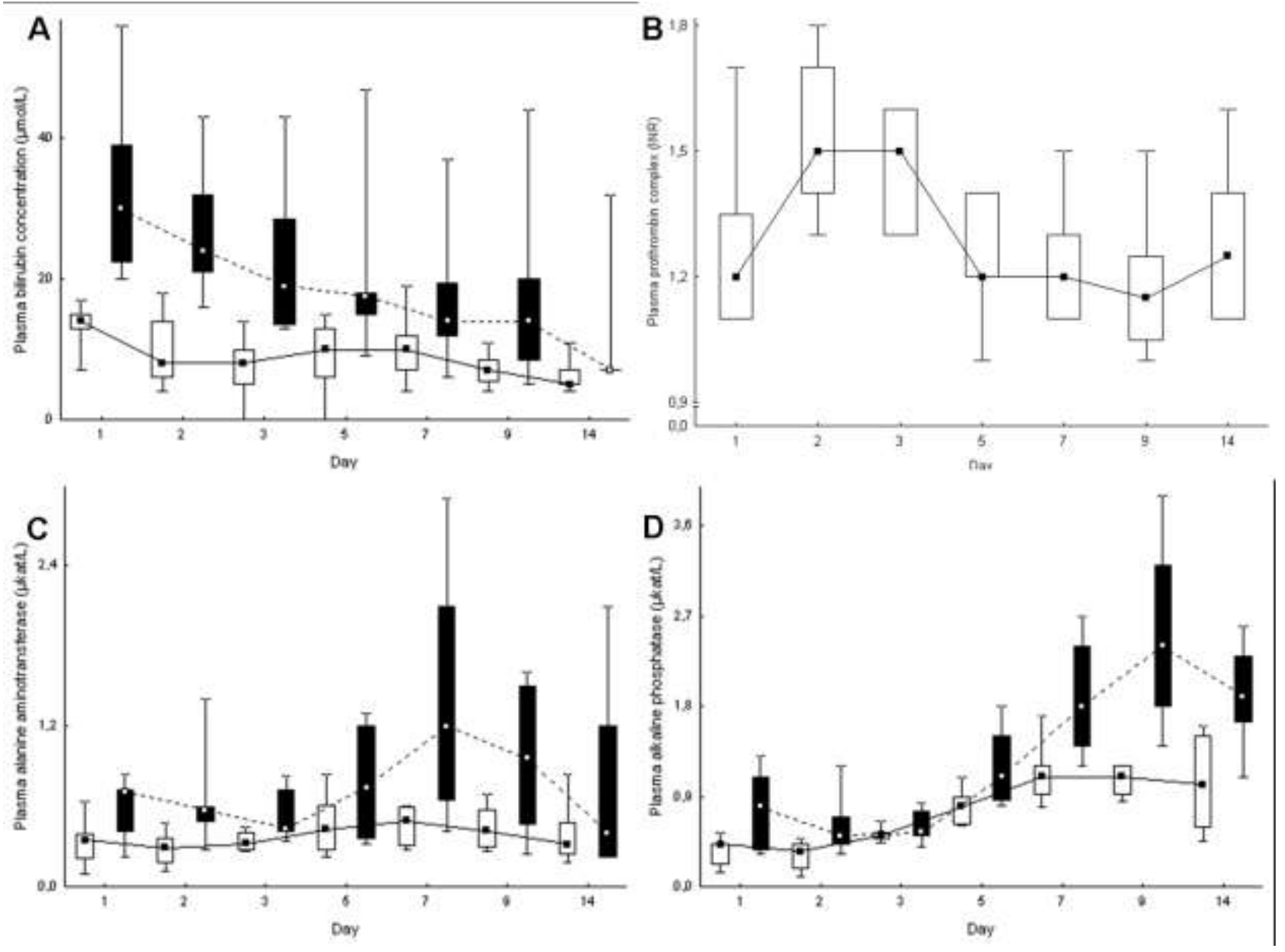

Figure 6. Static liver function tests, days 1-14 after injury. A=plasma bilirubin concentration: patients with bilirubin values no higher than $19 \mu \mathrm{mol} / \mathrm{L}$ ( $\mathrm{n}=9$; open boxes); patients with bilirubin values $20 \mu \mathrm{mol} / \mathrm{L}$ and higher ( $\mathrm{n}=8$; closed boxes). $\mathrm{B}=$ plasma prothrombin complex (international normalised ratio; INR) $(\mathrm{n}=17)$, all patients had values above the reference 1.2 INR. $\mathrm{C}=$ plasma alanine aminotransferase activity: patients with values no higher than 1.1 $\mu \mathrm{kat} / \mathrm{L}$ ( $\mathrm{n}=11$; open boxes); patients with values $1.2 \mu \mathrm{kat} / \mathrm{L}$ and higher ( $\mathrm{n}=6$; closed boxes). $\mathrm{D}=$ plasma alkaline phosphatase activity: patients with values no higher than $1.80 \mu \mathrm{kat} / \mathrm{L}$ ( $\mathrm{n}=6$; open boxes); patients with values $1.90 \mu \mathrm{kat} / \mathrm{L}$ and higher $(\mathrm{n}=11$; closed boxes). Squares indicate the median, boxes extend from $25^{\text {th }}$ to $75^{\text {th }}$ centile, and error bars show the $10^{\text {th }}$ and $90^{\text {th }}$ centiles. 


\subsection{Organ dysfunction and failure}

All patients had dysfunction of at least three of the five SOFA organ dimensions used, and it occurred during the first week in all the organs assessed (median onset ranged from days 1-3). The organs showed different patterns of dysfunction both in severity and time course during the study period. Respiratory and cardiovascular dysfunction were the most common $(\mathrm{n}=17)$ and the most severe, the median onset being day 1 (1.0-2.4), and the dysfunction persisted throughout the study period. Coagulation dysfunction was also common $(n=17)$ and severe, but not as persistent, median onset being on day 2 (1.6-3.0), and before the first operation in half the study group (8/17). Renal dysfunction developed in 13 patients, median onset day 3 (1-7). Two of the 13 patients required renal replacement on days 9 and 14, respectively, and another 4 required it later during their hospital stay. The least common, least severe, and least persistent, was hepatic dysfunction according to the SOFA score (plasma bilirubin concentration $20 \mu \mathrm{mol} / \mathrm{L}$ or higher), which was found in 8 patients, and after day 2 it had returned to normal in almost all of them (Fig. 7).

Twelve of the 17 patients developed multiple organ failure during the study period, median onset being on day 2 (1.5- 2.5). Five of these patients were in the liver dysfunction group and their multiple organ failure presented on days 1-2, while the multiple organ failure in the 7 patients in the no liver dysfunction group started on day 5 (3.0-8.4).

Four indicators of resuscitation (from day 1) were associated with the highest SOFA score during days 5-18 in one SOFA dimension each. They were: total intravenous fluids given associated with the SOFA cardiovascular dimension (rho 0.51, $<<0.05$ ); urine output associated with SOFA hepatic dimension (rho 0.63, $\mathrm{p}<0.05$ ); lowest arterial blood $\mathrm{pH}$ associated with SOFA respiratory dimension (rho $-0.52, \mathrm{p}<0.05$ ), and arterial base excess associated with SOFA renal dimension (rho $-0.61, \mathrm{p}<0.05)$. 


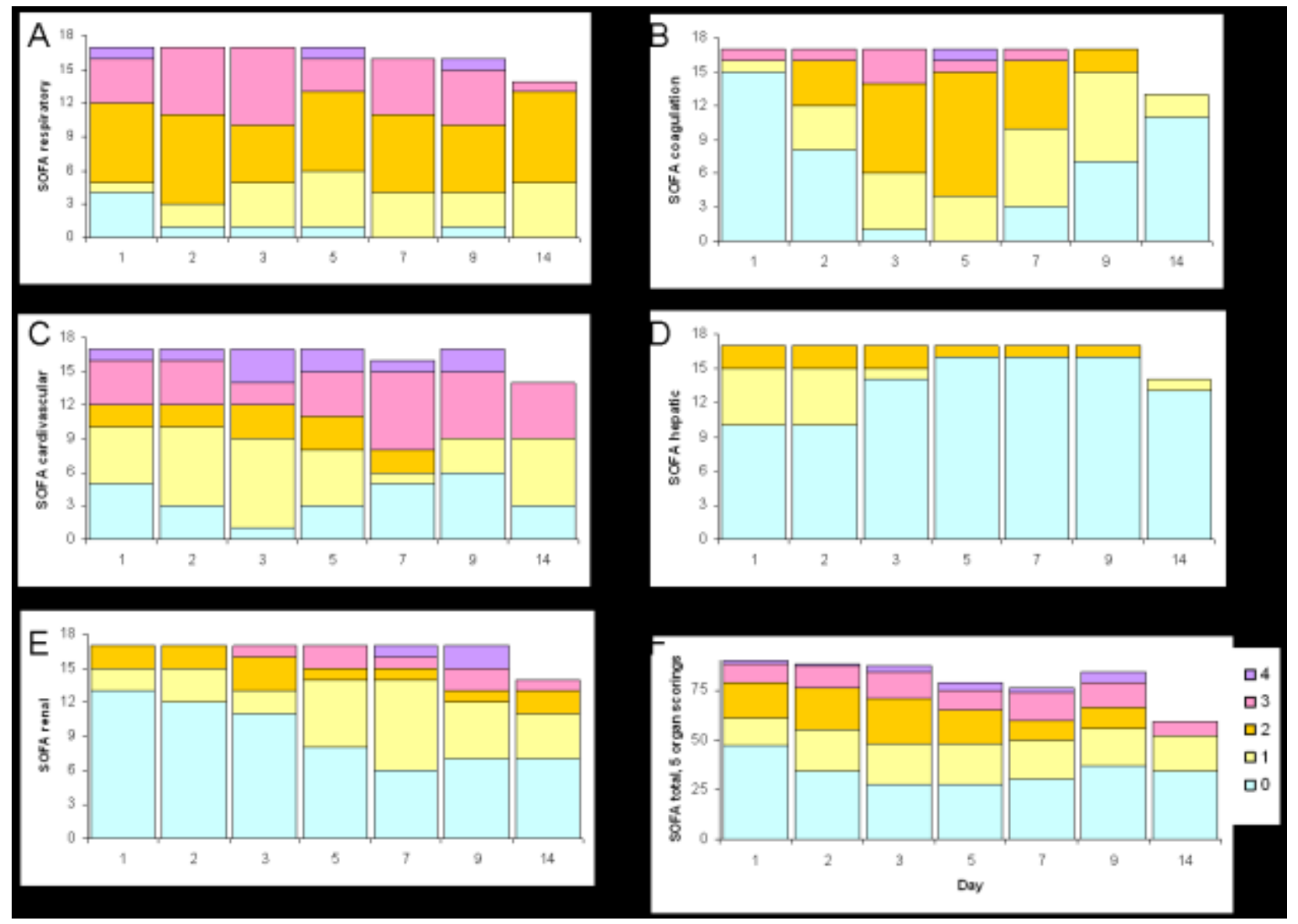

Figure 7. Dysfunction patterns (A-D) in different organs over the study period displayed as number of patients who scored $0,1,2,3$, or 4 SOFA points $(A=$ respiratory; $B=$ coagulation; $\mathrm{C}=$ cardiovascular; $\mathrm{D}=$ hepatic; and $\mathrm{E}=$ renal dimension), and $(\mathrm{F})$ is the number of patients who scored $0,1,2,3,4$ in all SOFA dimensions used $(5 \times 17$ patients $=85$ possible values/day). Score values from 0 to 4 are indicated with colours from light blue to purple. SOFA= Sequential Organ Failure Assessment score.

\subsection{Sepsis and ARDS}

Sepsis and ARDS were common in both groups (Table 1), and the median onset was on day 4.0 (3.4-8.6) for sepsis and on day 3.0 (1.2-7.6) for ARDS. All 6 patients who had plasma

ALT activity above the reference range developed sepsis before or on the same day, but another 8 patients also developed sepsis without plasma ALT activity being above the reference range.

\subsection{Enteral dysfunction}

Enteral dysfunction developed after other organs became dysfunctional. Five patients had episodes of inability to take enteral feeds with interruptions of more than 24 hours during the 
study period. The first episode occurred on median day 10.0 (8.4-11.6), after an episode of sepsis in all cases. Four of the patients with enteral dysfunction were classified as having no liver dysfunction, and the enteral dysfunction occurred on days when their PDR ICG $_{\text {G }}$ measurements were within or above the reference values.

\subsection{Hypermetabolic state and inflammation}

Plasma C-reactive protein concentrations were increased from $0 \mathrm{mg} / \mathrm{L}(0-72.0)$ on day 1 to $181.0 \mathrm{mg} / \mathrm{L}(125.0-288.0)$ on day $5(\mathrm{p}<0.001)$, and the median remained above $180 \mathrm{mg} / \mathrm{L}$ during the rest of the study period. The expiratory minute volume was $152.6 \mathrm{ml} / \mathrm{kg}$ predicted body weight (121.8-207.5) on day1, and increased during the study period to $197.8 \mathrm{ml} / \mathrm{kg}$ predicted body weight $(162.2-271.6)(\mathrm{p}<0.001)$ on day 14 . 


\section{Discussion}

To our knowledge this is the first time dynamic liver function has been studied in burned patients using $\mathrm{PDR}_{\mathrm{ICG}}$ together with measurement of static liver function tests, variables of the central circulation, and a detailed recording of organ dysfunction and failure. The PDR ICG $_{\text {. }}$ seems to give a comprehensive assessment of liver function after major burns. Early transient liver dysfunction was common, and persistent dysfunction was associated with death. A new and important finding is that liver dysfunction seems to be as common as dysfunction in any other organ, and we interpret the effects on liver function as a part in a multiple organ dysfunction syndrome that is primarily induced by the burn. However, this needs to be investigated further.

\subsection{Model chosen}

The inclusion criteria in the present study were chosen so that the group would comprise patients with severe burns who had a high probability of developing organ dysfunction and failure. We have previously used this strategy to select patients for the assessment of acute kidney injury [22], respiratory dysfunction [21, 25], and cardiac dysfunction [24]. From that

perspective this model seems to be reproducible, as the results are congruent between studies (early onset; the occurrence of organ dysfunction and sepsis; age and TBSA\% are important independent variables for dysfunction and outcome).

\subsection{Plasma disappearance rate of indocyanine green}

The results of the dynamic $\mathrm{PDR}_{\mathrm{ICG}}$ method showed that there seems to be a burn-induced effect on liver function that is partially associated with changes in static liver function tests, but also associated with factors that are well-known to be important in the outcome after a burn. 
When liver function has been assessed with PDR $_{\text {ICG }}$ in critically ill patients mean values between $12 \%-17 \% /$ minute have been reported [10, 26, 27], while elective surgical patients present with mean values of 19\%-23\%/minute [28, 29], which are within the reference range suggested by the LiMON manual (18\%-25\%/minute). Our study median PDR $\mathrm{ICG}_{\text {of }}$ $18.3 \% /$ minute (on day 1) was in between the results from these other two groups of patients.

There seems to be a breakpoint for mortality at the values $16 \%$ and $8 \% /$ minute among critically ill patients $[7,10]$, but correspondingly low values have been measured among patients having elective operations who survived [29]. Our results suggest that persistently and decreasing low values (below 16\%/minute) are associated with mortality among patients with severe burns, but the predictive value of low PDR $_{\text {ICG }}$ could not be fully tested in our study because there were so few deaths.

From the present study it is not possible to discern which specific mode of injury or cellular changes that caused the variations that were found in the PDR $\mathrm{ICG}_{\mathrm{IC}}$ measurements. There are several mechanisms that theoretically can cause liver damage after thermal injury, such as: ischemia-reperfusion injuries occurring immediately after the burn; the inflammatory response leading to increased levels of proinflammatory cytokines and other signals for apoptosis; and possibly (more mechanical mechanisms such as) hepatic oedema and fatty changes in the hepatocytes [30]. Experimental thermal injury has been shown to induce widespread liver cell apoptosis associated with caspase activation. Depletion of endoplasmic reticulum (ER) calcium result in an ER stress response with increased cytosolic calcium concentrations and mitochondrial damage [31]. Experimental hemorrhagic shock with hypovolemia has been shown to induce adenosine triphosphate (ATP) depletion and pericentral necrosis in the liver. Liver function as assessed by ICG clearance can remain decreased to $60 \%$ of baseline after 5 hours of resuscitation whereas tissue ATP is restored by the resuscitation [32]. Increased rate of ICG uptake into the hepatocyte can be due to the 
inflammatory response. The genes encoding the basolateral hepatocyte ICG transporters have been shown to be upregulated by inflammatory stimulation [10].

\subsection{Multiple organ dysfunction and plasma disappearance rate of indocyanine green}

The question remains, however, whether the common and early onset of liver dysfunction that we found is part of a multiple organ dysfunction syndrome, or whether it is merely a physiological response to a burn. In favour of multiple organ dysfunction is that we found early changes in a number of other organ systems, which could be classified as dysfunction or failure, and which suggest that the changes we found in liver function also reflect a state of dysfunction.

The fact that we did not find significant associations in the regression model between

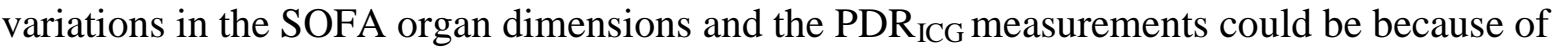
differences in the progression pattern, as a timely delay between variables can counteract regression. Whether this difference resulted from a different pattern of dysfunction or from the choice of markers cannot be established from our results. The observation that mortality was high among the patients with low and decreasing PDR $_{\text {ICG }}$ values also supports the argument that the effects on the liver that were measured by PDR ICG $_{\text {are relevant. }}$ Pathological studies have reported that up to $20 \%$ of thermally injured patients who have necropsies have signs of liver necrosis [33-35], and fatty infiltration of the liver is a common necropsy finding among children with large burns [34]. However, from the results of our study we do not know if decreasing liver function measured by PDR ICG $_{\text {before death is a }}$ marker of imminent acute liver failure or just a sign of the dying process.

\subsection{Liver dysfunction, static tests}

Our findings of the common occurrence and early onset of abnormal liver functions based on PDR $_{\text {ICG }}$ have not previously been reported among adult burned patients, but are in line with results from studies in children [5]. The initial release of hepatic enzymes found in children has been shown to be substantially higher and peaked much earlier $[5,36]$ than those from our 
study, possibly because of the greater extent of injury among the children compared with our patients. We found an overall association between plasma bilirubin concentration and

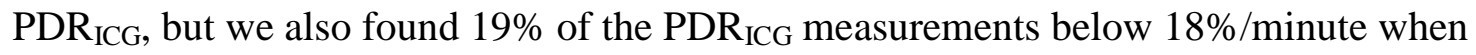
plasma bilirubin concentration was not increased $(<20 \mu \mathrm{mol} / \mathrm{L})$, suggesting that $\mathrm{PDR}_{\mathrm{ICG}}$ is more sensitive to liver dysfunction than plasma bilirubin; this is in line with previous findings among critically ill patients [10], and it can explain that we found a relatively high incidence of liver dysfunction in our study compared to studies that have assessed static liver dysfunction among adult burned patients $[3,4]$. We did not find increased plasma bilirubin concentrations on day 1 among the patients with the largest TBSA\%, including deep burns. An early and transient increase in plasma bilirubin concentration could be caused by haemolysis from capillaries in the burned skin, but if the burn is deep enough (coagulation of capillaries) to prevent perfusion of haemolysed blood into the central circulation the concentrations can theoretically be within the reference range.

We also found $10 \%$ of the $\mathrm{PDR}_{\mathrm{ICG}}$ measurements above $18 \% /$ minute when plasma bilirubin concentration was increased, and this could be the result of differences in hepatocellular transport gene expression for ICG and bilirubin [10].

\subsection{Other important and relevant findings}

Firstly, the fact that we did not find significant associations between resuscitation indicators (day 1) and liver dysfunction (lowest $\mathrm{PDR}_{\mathrm{ICG}}$ measurement during the study period) suggests that the recorded liver dysfunction was not the result of shortcomings in resuscitation. However, we cannot rule out the possibility of local shortcomings in resuscitation as the indicators for resuscitation were measured in the central circulation. It is also possible that we have missed recording periods of severe hypoperfusion and acidosis both from the period before admission and after admission, as we did not monitor all resuscitation variables continuously. 
Secondly, some of the variables studied suggest a "two-hit" course over the study period, taking the onset of sepsis on day 4 as the second trigger. Animal studies have shown that the effect of a second hit on the hepatic circulation is more pronounced than the initial effects of the burn [37]. The "two-hit" course was not as apparent from the PDR $\mathrm{ICG}_{\mathrm{ICG}}$ measurements, as we found both decreasing $(n=5)$ and increasing $(n=5)$ values after the onset of sepsis. Sepsis was common, and its onset was not reflected in variations in the results of static liver function tests in all patients.

\subsection{Limitations}

The one-centre approach with results generated from a relatively small study group is a limitation that can make it difficult to generalise the result. One advantage with a singlecentre study is that the population is less heterogeneous and the effects of different treatments and regimens are reduced, an advantage that is further supported by the strict protocol for the treatment of burns at the unit [15], which can strengthen the value of the results.

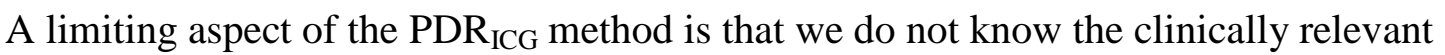
reference range among patients with major burns, or different age groups. However, it is a reasonable assumption that high $\mathrm{PDR}_{\mathrm{ICG}}$ values should be expected during the hypermetabolic and hypercirculatory phase after a severe burn, and that "normal" $P D R_{I C G}$ values may be pathological. It is therefore possible that we have underestimated the incidence of liver dysfunction in the present study. However, because we had no direct measurements of hepatic

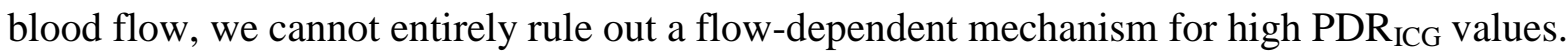

A recent study has shown that albumin synthesis is enhanced at the end of the second week after injury among young adults with severe burns [38]. This is in line with our findings

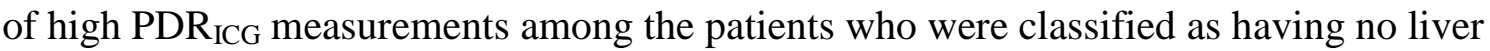
dysfunction. Both increased hepatic uptake of ICG and increased synthesis of albumin, even if not reflecting the same function in the hepatocyte, can be due to the hypermetabolic state after burns, and our data suggest that the hypermetabolic response in liver function is more 
pronounced among young adults. The median age in our study among the patients $(n=6)$ who

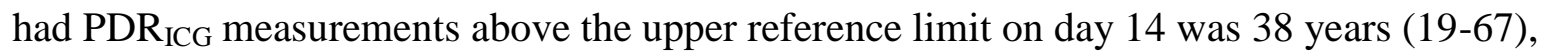
which was closer to the mean age of 29 years of the five patients studied by Martini et al. [38] than to the median age of 65.5 years $(20-85)$ among the patients $(n=8)$ in our study who had $\mathrm{PDR}_{\mathrm{ICG}}$ measurements within or below reference on day 14 . It is also in line with our findings from a previous study of eight young adult patients who showed an increased elimination rate of ethanol after burns compared to healthy controls [39]. In that study median age was 39 years (29-54) and TBSA was $28 \%$ (19-71). It is well known that there are age-related changes that affect liver structure and function $[40,41]$ but, as we adjusted for age-related changes by including age in the regression model, we do not think that it interferes with our conclusion. However, further studies are needed to find out the clinically relevant, and age-adjusted, reference range.

\section{Conclusions}

To our knowledge this is the first time dynamic liver function has been studied in burned patients using PDR $_{\mathrm{ICG}}$ together with static liver function tests and variables that reflect the central circulation. The $\mathrm{PDR}_{\mathrm{ICG}}$ seems to give a comprehensive assessment of liver function after major burns. The development of liver dysfunction seems to be as common as dysfunction in other organs, and we interpret the effects seen on liver function as a part in a multiple organ dysfunction syndrome, primarily induced by the burn. Somewhat unexpectedly we found a large number of high $\mathrm{PDR}_{\mathrm{ICG}}$ measurements, and our results indicate that the burn induced inflammatory and hypermetabolic state plays a substantial part in the high PDR $_{\text {ICG }}$ values. It is therefore possible that we have underestimated the incidence of liver dysfunction

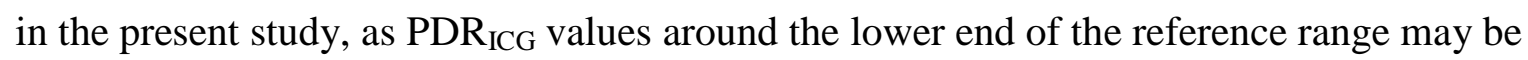


indicative of insufficient hepatic perfusion or insufficient hepatic functional reserve.

However, this needs to be further investigated.

\section{Conflict of interest}

The authors declare that they have no competing interests. 


\section{Acknowledgements}

The study was done at the Burns Unit and financed by the Department of Hand and Plastic Surgery Linköping University Hospital. The study was supported (placement of a study devise, part of the ICG and disposables) by PULSION Medical Systems AG, Stahlgruberring 28, 81829 Munich, Germany. 


\section{References}

[1] Price LA, Thombs B, Chen CL, and Milner SM. Liver disease in burn injury: evidence from a national sample of 31,338 adult patients. J Burns Wounds 2007;7:e1.

[2] 2010 National Burn Repository Report [cited; Available from: http://www.ameriburn.org/2010NBRAnnualReport.pdf.

[3] Cumming J, Purdue GF, Hunt JL, and O'Keefe GE. Objective estimates of the incidence and consequences of multiple organ dysfunction and sepsis after burn trauma. J Trauma 2001;50:510-5.

[4] Sheridan RL, Ryan CM, Yin LM, Hurley J, and Tompkins RG. Death in the burn unit: sterile multiple organ failure. Burns 1998;24:307-11.

[5] Jeschke MG, Micak RP, Finnerty CC, and Herndon DN. Changes in liver function and size after a severe thermal injury. Shock 2007;28:172-7.

[6] Sakka SG. Assessing liver function. Curr Opin Crit Care 2007;13:207-14.

[7] Sakka SG, Reinhart K, and Meier-Hellmann A. Prognostic value of the indocyanine green plasma disappearance rate in critically ill patients. Chest 2002;122:1715-20.

[8] Inal MT, Memis D, Kargi M, and Sut N. Prognostic value of indocyanine green elimination assessed with LiMON in septic patients. J Crit Care 2009;24:329-34.

[9] Kimura S, Yoshioka T, Shibuya M, Sakano T, Tanaka R, and Matsuyama S. Indocyanine green elimination rate detects hepatocellular dysfunction early in septic shock and correlates with survival. Crit Care Med 2001;29:1159-63.

[10] Kortgen A, Paxian M, Werth M, Recknagel P, Rauchfuss F, Lupp A, et al. Prospective assessment of hepatic function and mechanisms of dysfunction in the critically ill. Shock 2009;32:358-65. 
[11] Sakka SG and van Hout N. Relation between indocyanine green (ICG) plasma disappearance rate and ICG blood clearance in critically ill patients. Intensive Care Med 2006;32:766-9.

[12] Sakka SG, Reinhart K, and Meier-Hellmann A. Comparison of invasive and noninvasive measurements of indocyanine green plasma disappearance rate in critically ill patients with mechanical ventilation and stable hemodynamics. Intensive Care Med 2000;26:1553-6.

[13] Faybik P, Krenn CG, Baker A, Lahner D, Berlakovich G, Steltzer H, et al. Comparison of invasive and noninvasive measurement of plasma disappearance rate of indocyanine green in patients undergoing liver transplantation: a prospective investigator-blinded study. Liver Transpl 2004;10:1060-4.

[14] Ventilation with lower tidal volumes as compared with traditional tidal volumes for acute lung injury and the acute respiratory distress syndrome. The Acute Respiratory Distress Syndrome Network. N Engl J Med 2000;342:1301-8.

[15] Sjoberg F, Danielsson P, Andersson L, Steinwall I, Zdolsek J, Ostrup L, et al. Utility of an intervention scoring system in documenting effects of changes in burn treatment Burns 2000;26:553-9.

[16] Levy MM, Fink MP, Marshall JC, Abraham E, Angus D, Cook D, et al. 2001 SCCM/ESICM/ACCP/ATS/SIS International Sepsis Definitions Conference. Crit Care Med 2003;31:1250-6.

[17] Lorente JA, Vallejo A, Galeiras R, Tomicic V, Zamora J, Cerda E, et al. Organ dysfunction as estimated by the sequential organ failure assessment score is related to outcome in critically ill burn patients. Shock 2009;31:125-31.

[18] Vincent JL, de Mendonca A, Cantraine F, Moreno R, Takala J, Suter PM, et al. Use of the SOFA score to assess the incidence of organ dysfunction/failure in intensive care units: results of a multicenter, prospective study. Working group on "sepsis-related 
problems" of the European Society of Intensive Care Medicine. Crit Care Med 1998;26:1793-800.

[19] Greenhalgh DG, Saffle JR, Holmes JHt, Gamelli RL, Palmieri TL, Horton JW, et al. American Burn Association consensus conference to define sepsis and infection in burns. J Burn Care Res 2007;28:776-90.

[20] Murray JF, Matthay MA, Luce JM, and Flick MR. An expanded definition of the adult respiratory distress syndrome. Am Rev Respir Dis 1988;138:720-3.

[21] Steinvall I, Bak Z, and Sjoberg F. Acute respiratory distress syndrome is as important as inhalation injury for the development of respiratory dysfunction in major burns. Burns 2008;34:441-51.

[22] Steinvall I, Bak Z, and Sjoberg F. Acute kidney injury is common, parallels organ dysfunction or failure, and carries appreciable mortality in patients with major burns: a prospective exploratory cohort study. Crit Care 2008;12:R124.

[23] Bak Z, Sjoberg F, Eriksson O, Steinvall I, and Janerot-Sjoberg B. Hemodynamic changes during resuscitation after burns using the Parkland formula. $\mathbf{J}$ Trauma 2009;66:329-36.

[24] Bak Z, Sjoberg F, Eriksson O, Steinvall I, and Janerot-Sjoberg B. Cardiac dysfunction after burns. Burns 2008;34:603-9.

[25] Liffner G, Bak Z, Reske A, and Sjoberg F. Inhalation injury assessed by score does not contribute to the development of acute respiratory distress syndrome in burn victims. Burns 2005;31:263-8.

[26] Sakka SG, Koeck H, and Meier-Hellmann A. Measurement of indocyanine green plasma disappearance rate by two different dosages. Intensive Care Med 2004;30:5069.

[27] Michelet P, Roch A, Gainnier M, Sainty JM, Auffray JP, and Papazian L. Influence of support on intra-abdominal pressure, hepatic kinetics of indocyanine green and 
extravascular lung water during prone positioning in patients with ARDS: a randomized crossover study. Crit Care 2005;9:R251-7.

[28] Sakka SG, Hofmann D, Thuemer O, Schelenz C, and van Hout N. Increasing cardiac output by epinephrine after cardiac surgery: effects on indocyanine green plasma disappearance rate and splanchnic microcirculation. J Cardiothorac Vasc Anesth $2007 ; 21: 351-6$

[29] Reekers M, Simon MJ, Boer F, Mooren RA, van Kleef JW, Dahan A, et al. Pulse dye densitometry and indocyanine green plasma disappearance in ASA physical status I-II patients. Anesth Analg 2010;110:466-72.

[30] Jeschke MG. The hepatic response to thermal injury: is the liver important for postburn outcomes? Mol Med 2009;15:337-51.

[31] Jeschke MG, Gauglitz GG, Song J, Kulp GA, Finnerty CC, Cox RA, et al. Calcium and ER stress mediate hepatic apoptosis after burn injury. J Cell Mol Med 2009;13:1857-65.

[32] Paxian M, Bauer I, Rensing H, Jaeschke H, Mautes AE, Kolb SA, et al. Recovery of hepatocellular ATP and "pericentral apoptosis" after hemorrhage and resuscitation. Faseb J 2003;17:993-1002.

[33] Gomez R, Murray CK, Hospenthal DR, Cancio LC, Renz EM, Holcomb JB, et al. Causes of mortality by autopsy findings of combat casualties and civilian patients admitted to a burn unit. J Am Coll Surg 2009;208:348-54.

[34] Barret JP, Jeschke MG, and Herndon DN. Fatty infiltration of the liver in severely burned pediatric patients: autopsy findings and clinical implications. J Trauma $2001 ; 51: 736-9$

[35] Iliopoulou E, Markaki S, and Poulikakos L. Autopsy findings in burn injuries. Arch Anat Cytol Pathol 1993;41:5-8. 
[36] Jeschke MG, Chinkes DL, Finnerty CC, Kulp G, Suman OE, Norbury WB, et al. Pathophysiologic response to severe burn injury. Ann Surg 2008;248:387-401.

[37] Tadros T, Traber DL, and Herndon DN. Hepatic blood flow and oxygen consumption after burn and sepsis. J Trauma 2000;49:101-8.

[38] Martini WZ, Wolf SE, Chinkes DL, Chung KK, Dubick MA, Blackbourne L, et al. Enhanced albumin synthesis in severely burned adults. Shock 2010;34:364-8.

[39] Zdolsek HJ, Sjoberg F, Lisander B, and Jones AW. The effect of hypermetabolism induced by burn trauma on the ethanol-oxidizing capacity of the liver. Crit Care Med $1999 ; 27: 2622-5$.

[40] Wakabayashi H, Nishiyama Y, Ushiyama T, Maeba T, and Maeta H. Evaluation of the effect of age on functioning hepatocyte mass and liver blood flow using liver scintigraphy in preoperative estimations for surgical patients: comparison with CT volumetry. J Surg Res 2002;106:246-53.

[41] Suttner SW, Surder C, Lang K, Piper SN, Kumle B, and Boldt J. Does age affect liver function and the hepatic acute phase response after major abdominal surgery? Intensive Care Med 2001;27:1762-9. 
Table 1. Details of all patients, and of the two groups of liver function.

\begin{tabular}{lllll}
\hline & All patients & Liver dysfunction & No liver dysfunction & p value \\
\hline Patients & 17 & 7 & 10 & \\
Age (years) & $46.0(20.0-79.0)$ & $70.0(40.0-85.0)$ & $38.0(19.5-77.5)$ & 0.04 \\
TBSA\% & $33.0(21.5-70.0)$ & $32.0(22.5-70.0)$ & $37.6(21.3-70.8)$ & 0.88 \\
FTB\% & $24.8(0.3-49.0)$ & $25.0(0.5-49.0)$ & $21.9(0.1-57.5)$ & 0.53 \\
Sex (male/female) & $15 / 2$ & $7 / 0$ & $8 / 2$ & 0.33 \\
Pre existing medical condition & 9 & 4 & 5 & 0.58 \\
Duration of stay (days) & $66.0(10-116)$ & $49.0(9.0-98.0)$ & $73.5(21.0-125)$ & 0.46 \\
Days on mechanical ventilation & $40(9.0-86.0)$ & $22(9.0-86.0)$ & $45.5(11.0-90.0)$ & 0.41 \\
Inhalation injury & 6 & 3 & 3 & 0.48 \\
Operations/patient & $7(2.0-15.0)$ & $7(0-10.0)$ & $7(2.0-17.5)$ & 0.43 \\
Sepsis & 15 & 6 & 9 & 7 \\
ARDS & 13 & 6 & 2 & 0.67 \\
Mortality & 4 & 2 & 0.60
\end{tabular}


Data are presented as number of patients, or median (10-90 centiles). Total body surface area=TBSA\%; full thickness burn=FTB. Inhalation injury was defined by bronchoscopic evidence of mucosal injury such as erythema, oedema, ulceration, or sloughing. Sepsis and ARDS data were collected during the study period, other variables are during the hospital stay. ARDS=acute respiratory distress syndrome. 
Table 2. Associations between changes in liver function $\left(\mathrm{PDR}_{\mathrm{ICG}}\right)$ and physiological markers after serious burns.

\begin{tabular}{|c|c|c|c|c|}
\hline & Coef & $\mathrm{p}$ value & Beta* & Beta part* \\
\hline Age & -0.25 & $<0.001$ & -0.60 & 16.0 \\
\hline TBSA $\%$ & -0.14 & 0.02 & -0.28 & 7.5 \\
\hline Plasma bilirubin concentration & -0.25 & 0.001 & -0.38 & 10.2 \\
\hline Cardiac index & 2.45 & $<0.001$ & 0.33 & 8.8 \\
\hline Plasma C-reactive protein & -0.04 & $<0.001$ & -0.43 & 11.5 \\
\hline \multicolumn{5}{|c|}{ Multiple regression for longitudinal data, $\mathrm{PDR}_{\mathrm{ICG}}(\% /$ minute $)$ as dependent variable. } \\
\hline \multicolumn{5}{|c|}{ Variables that contributed significantly to the final result were retained in the model. } \\
\hline \multicolumn{5}{|c|}{ Model overall $\mathrm{R}^{2} 0.54$; between subjects $\mathrm{R}^{2} 0.77$; within subjects $\mathrm{R}^{2} 0.19$. *The relative } \\
\hline \multicolumn{5}{|c|}{ percentage (beta part) of the contribution from the included variables to a hypothetical $\mathrm{R}^{2}$} \\
\hline \multicolumn{5}{|c|}{1.00 was calculated $\left(\left(1\right.\right.$-overall $\left.\mathrm{R}^{2}\right)+$ overall $\left.\mathrm{R}^{2}\right)$ using the standardised coefficients (beta) } \\
\hline
\end{tabular}


Table 3. Measurements of central haemodynamics and extravascular lung water during the first 24 hours after injury.

\begin{tabular}{llll}
\hline & Survivors & Non survivors & P value \\
\hline Patients & $13^{*}$ & 4 & \\
Age (years) & $41.0(20.0-76.0)$ & $77.0(70.0-79.0)$ & 0.02 \\
TBSA\% & $39.0(22.5-70.0)$ & $29.6(21.0-33.0)$ & 0.16 \\
Cardiac index $\left(\mathrm{L} / \mathrm{min} / \mathrm{m}^{2}\right)$ & $2.6(1.7-4.3)$ & $2.9(1.9-3.9)$ & 0.84 \\
Intrathoracic blood volume index $\left(\mathrm{ml} / \mathrm{m}^{2}\right)$ & $675(455-1019)$ & $1042(633-1648)$ & 0.13 \\
Extravascular lung water index $\left(\mathrm{ml} / \mathrm{kgBW}^{2}\right)$ & $6.0(4.1-8.6)$ & $7.1(5.6-15.2)$ & 0.27 \\
Extravascular lung water/intrathoracic blood volume & $0.38(0.28-0.43)$ & $0.32(0.20-0.35)$ & 0.04 \\
Cardiac function index $(1 / \mathrm{min})$ & $4.2(3.7-5.9)$ & $3.5(2.5-3.9)$ & 0.02 \\
Systemic vascular resistance index $\left(\mathrm{dyn} \mathrm{s} \mathrm{cm}{ }^{-5} \mathrm{~m}^{2}\right)$ & $2479(1128-3330)$ & $2031(1330-4278)$ & 0.95
\end{tabular}

11 of the 13 patients who survived. 
